\title{
Biochemical classification of Klebsiella correlated with the severity of the associated disease
}

\author{
W. D. FOSTER AND JEAN BRAGG \\ From Dudley Road Hospital, Birmingham
}

SYNOPSIS The biochemical classification of the Klebsiella proposed by Cowan, Steel, Shaw, and흉 Duguid (1960) has been applied to 50 strains isolated as the pure or predominant growth from: sputum, and Klebsiella species have been correlated with the severity of the chest infection in the $e_{G}^{G}$ patient. A modification in nomenclature is suggested.

The clinico-pathological significance of the different species or strains belonging to the genus Klebsiella isolated from sputum is not known. The object of this study was to apply a biochemical scheme of classification to these organisms and to correlate the type of organism with the clinical features of the associated disease in the patient.

In 1882 Friedlander, studying sections of lungs taken at necropsy from cases of lobar pneumonia, demonstrated the presence of diplococci in large numbers. Extending this work in the following year he reported more detailed studies on the organism, including culture work. He observed and studied the capsules which he regarded as particularly characteristic of the causal organisms of lobar pneumonia and isolated organisms in pure culture on nutrient gelatine. However, puzzling features of the organism isolated in culture by Friedlander are that (1) it grew profusely on almost any medium; (2) it was not virulent for rabbits; (3) sometimes it was rod shaped. Obviously, since Friedlander was studying typical cases of lobar pneumonia, most of the organisms which he saw in his sections were pneumococci and indeed one of his colleagues, Dr. Gram of Copenhagen, developed his special staining technique, now so familiar, which stained the organisms blue. However, the organisms he managed to culture were clearly not pneumococci; they grew too readily and were not virulent to rabbits. A few of his cases of pneumonia must therefore have been of Klebsiella pneumonia. In a very short time the pneumococcus was characterized and through the work of Fraenkel, of Sternberg, and of Weichselbaum (abstracted by Bloomfield, 1958) shown to be the true cause of lobar pneumonia, and Friedlander, who was actually the first to describe adequately both the pneumococcus and Klebsiella, was saddled with the Received for publication 30 March 1962. bacillus which has so long borne his name (Bloom- $\stackrel{\circ}{?}$ field, 1958).

Friedlander's bacillus was soon shown to be responsible for only a small proportion of cases of $\overrightarrow{\mathbb{Q}}$ lobar pneumonia. However, the statement current $\bar{Z}$ in many textbooks that Friedlander's bacillus is $a \cong$ rare cause of pneumonia, being only responsible for $\overrightarrow{0}$ about $1 \%$ of cases, underestimates the importanee of this organism as a cause of chest infections. This is particularly true of hospital practice today sireo patients with so many of the commoner pneumo-s coccal infections are effectively treated at home ando only those more severely infected with Friedlander'so bacillus are admitted to hospital. Weiss, Eisenberg, Alexander, and Flippin (1954) reported 24 cases of pneumonia associated with Klebsiella in the sputum from the Philadelphia General Hospital in the single winter of 1952-53, though, since their criteria for the identification of a Klebsiella included a negative methyl red reaction, an important group of Klebsiellas was probably excluded.

In Dudley Road Hospital, out of sputum samples? from 900 patients recently examined, Klebsiella waş isolated as a pure or dominant growth in 50 cases 0 This figure is to be contrasted with only 33 for the pneumococcus and 90 for Staph. pyogenes.

There is general agreement that infection with the. true Friedlander's bacillus causes a particularlys severe type of pneumonia with a mortality between 25 and $50 \%$ and that in non-fatal cases the illness is prolonged and the pneumonia frequently goes on to $\sigma^{\omega}$ abscess formation. However, Friedlander's bacillus? is but one of the species of Klebsiella which may be isolated from sputum. Ørskov (1955) found that $9 \Phi_{2}$ strains of Klebsiella isolated from sputum could be divided into at least 60 capsular types and that contrary to the generally held opinion, types 1 to $\mathbb{F}_{0}$ constituted only $15.6 \%$ of the total. 
Different types of Klebsiella vary in their virulence for mice (Kauffmann, 1951) and it seems likely that the same holds for man, as only a minority of patients from whose sputum Klebsiella are cultured are severely ill. It is therefore desirable to be able to classify these organisms and, if possible, determine which are the dangerous types.

The Klebsiella may be grouped either by their antigenic structure or by their biochemical activities. By the former method the genus has been divided into 72 types on the basis of the capsular antigens. The value of this method in clinical practice is limited because the necessary sera for typing are numerous and not available commercially, and also very little work has been done on the clinicopathological significance of the different serotypes.

Until recently the value of biochemical tests in the classification of Klebsiella has been small. Wilson and Miles (1948) considered that 'there is so much variation between the different members within each group as to make the classification of any individual strain of unknown origin often impossible'. Recently, however, a new biochemical classification has been proposed by Cowan et al. (1960). This divides the Klebsiella into six types and in particular allows $K$. pneumoniae to be distinguished from $K$. aerogenes, from the practical point of view the most important change. The key characters are few and sufficiently simple to be well suited to a routine clinical laboratory.

The purpose of this study is to assess the value of this new biochemical classification in relation to the 50 strains of Klebsiella isolated from sputum which have already been mentioned and to attempt to correlate Klebsiella type with the clinico-pathological features of the patient. The criteria adopted as a preliminary screen for selecting Klebsiella from other coliform organisms were that it should be a Gramnegative, rod-shaped organism which fermented either adonitol or inositol within 48 hours. Most strains were also found to possess capsules.

\section{METHODS}

The samples of sputum, which were received at the laboratory in universal containers, were homogenized using buffered pancreatin solution (Rawlins, 1955). A loopful was then spread on a glass slide and stained by Gram's method for microscopical examination. Cultures were made on $5 \%$ horse blood agar plates and examined after overnight incubation at $37^{\circ} \mathrm{C}$. From cultures showing a pure or predominant growth of 'coliform'- like colonies wet nigrosin preparations for capsules and inoculations into adonitol and inositol were made.

ANTIBIOTIC SENSITIVITY TESTS These tests were performed by inoculating plates of Oxoid sensitivity agar and applying an Oxoid Multodisc impregnated with penicillin 5 units, streptomycin $25 \mu \mathrm{g}$., tetracycline $50 \mu \mathrm{g}$., erythromycin $50 \mu \mathrm{g}$., novobiocin $30 \mu \mathrm{g}$., chloramphenicol $50 \mu \mathrm{g}$., and sulphonamide $500 \mu \mathrm{g}$.

FERMENTATION TESTS One per cent sugars in peptone water were inoculated and incubated at $37^{\circ} \mathrm{C}$. for 48 hours.

CITRATE UTILIZATION Oxoid Simmons citrate agar slopes were inoculated and incubated at $37^{\circ} \mathrm{C}$. overnight.

UREASE PRODUCTION Christensen's urea agar slopes were inoculated and incubated at $37^{\circ} \mathrm{C}$. for 48 hours.

GLUCONATE OXIDATION The method of Shaw and Clarke (1955) was employed.

GROWTH IN KCN The method was that used in the Salmonella Reference Laboratory, Colindale (Dr. Joan Taylor, personal communication), a modification of that described by Møller (1954).

Table I reproduces the diagnostic scheme of Cowan $e t$ $a l$. in full but in this study only certain of the characters were tested. On the basis of this reduced number of tests it was possible to obtain a clear distinction between the different species of Klebsiella.

TABLE I

DIAGNOSTIC SCHEME OF COWAN $e t$ al. (1960)

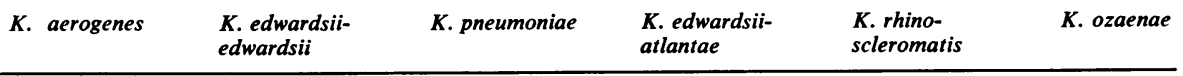

\begin{tabular}{|c|c|c|c|c|c|c|}
\hline Fimbriae & + & - & + & - & - & - \\
\hline Gas from glucose ${ }^{1}$ & + & - & + & + & - & + \\
\hline Lactose (acid) ${ }^{2}$ & + & $(+)$ & + & $(+)$ & - & $(+)$ \\
\hline Methyl red ${ }^{1}$ & - & d & + & + & + & + \\
\hline Voges-Proskauer ${ }^{1}$ & + & + & - & d & - & - \\
\hline Citrate 1 & + & d & + & + & - & d \\
\hline Urease $^{1}$ & + & + & + & + & - & d \\
\hline Gluconate ${ }^{1}$ & + & + & d & d & - & - \\
\hline Malonate & + & d & + & - & + & - \\
\hline Lysine decarboxylase & + & + & + & + & - & - \\
\hline $44^{\circ}$ test & d & - & - & - & - & - \\
\hline Dulcitol (acid) 1 & d & - & + & - & - & - \\
\hline $\mathbf{K C N}^{1}$ & + & + & - & + & + & + \\
\hline
\end{tabular}


MOUSE VIRULENCE TESTS A small portion of a Klebsiella colony was emulsified in peptone water to give minimal opalescence and $0.1 \mathrm{ml}$. injected intraperitoneally. The test was considered to be negative if the animal survived more than $\mathbf{7 2}$ hours. From all positive cases the organism was recovered from the heart blood after death.

CLINICAL ASSESSMENT The pathogenicity of the different Klebsiella strains for man has been roughly assessed by dividing the patients from whom strains were recovered into three groups according to the severity of their disease.

Group 1 Cases of fatal infections or pneumonia which ended in abscess formation.

Group 2 Cases diagnosed clinically as pneumonia in which there was radiological evidence of pulmonary consolidation.

Group 3 Cases of bronchitis and other chest infections in which there was no radiological evidence of consolidation.

\section{RESULTS}

The results of this investigation are presented in tabular form. The biochemical tests adopted allowed all the strains tested to be placed without difficulty into one of the six types. The methyl red and Voges-Proskauer reactions clearly differentiated the $K$. aerogenes from the other species; $K$. pneumoniae was separated from $K$. edwardsii by its failure to grow in $\mathrm{KCN}$ and its fermentation of dulcite. The two varieties of $K$. edwardsii gave very similar $\stackrel{0}{=}$

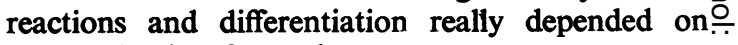
gas production from glucose.

\section{DISCUSSION}

From a consideration of these results a number of $\frac{\sqrt{5}}{\bar{\Phi}}$ points emerge which may be discussed in turn.

This investigation shows that the biochemicates classification of the Klebsiella proposed by Cowanet al. (1960) is useful in clinical practice. It is not necessary to test each of the characters given in $\vec{\omega}$ their table in order to arrive at an identification. The nine characters selected for test in this study areo quite adequate to allow the various species to be $\vec{G}$ recognized and tests can be performed convenientlyer in a clinical laboratory so that the identification can be made within 48 hours.

As can be seen from Table II the variability of the reactions of the strains corresponds well with the criteria laid down by Cowan et al. It should bed noted that $a$ ' + ' character in their scheme denotes reaction which is positive in over $75 \%$ of cases, $a$ " character one which is positive in less than $25 \%$, an a ' $d$ ' character one which is positive in between 25 . and $75 \%$ of cases. On this basis the present collectiong of strains shows discrepancies in the reactions ${ }^{2} \mathrm{~F}^{3}$ those strains assigned to the species $K$. edwardsii 政冧 edwardsii but this is probably of little significance

TABLE II

BIOCHEMICAL REACTIONS OF THE 50 STRAINS TESTED

\begin{tabular}{|c|c|c|c|c|c|c|c|c|c|c|}
\hline & & \multirow{2}{*}{ Urease } \\
\hline & $\begin{array}{l}\text { No. of } \\
\text { Strains }\end{array}$ & $\begin{array}{l}\text { Glucose } \\
\text { Gas }\end{array}$ & Lactose & $\begin{array}{l}\text { Methyl } \\
\text { Red }\end{array}$ & $\begin{array}{l}\text { Voges- } \\
\text { Proskauer }\end{array}$ & $K C N$ & Gluconate & Dulcite & Citrate & \\
\hline K. aerogenes & 31 & 30 & 31 & $\mathbf{0}$ & 31 & 31 & 30 & 14 & 31 & 21 \\
\hline K. edwardsii-edwardsii & 8 & 0 & 7 & 8 & 3 & 8 & 5 & $\mathbf{0}$ & 5 & 4 \\
\hline K. edwardsii-atlantae & 6 & 6 & 6 & 6 & 3 & 6 & 3 & $\mathbf{0}$ & 6 & 4 \\
\hline K. pneumoniae & 4 & 4 & 3 & 4 & $\mathbf{0}$ & 0 & $\mathbf{0}$ & 4 & 3 & 1 \\
\hline K. rhinoscleroma & 1 & 0 & 1 & 1 & $\mathbf{0}$ & 1 & $\mathbf{0}$ & $\mathbf{0}$ & 0 & \\
\hline
\end{tabular}

TABLE III

RESULTS OF MOUSE VIRULENCE TESTS AND CORRELATION BETWEEN SEVERITY OF DISEASE AND SPECIES OF KLEBSIELLA

\begin{tabular}{lllll} 
No. of Strains & No. Mouse Virulent & No. of Patients in & Grade II \\
\cline { 3 - 5 } & Grade I & Grade ID \\
\hline
\end{tabular}

\begin{tabular}{|c|c|c|c|c|c|}
\hline $\begin{array}{l}K . \text { aerogenes } \\
K . \text { edwardsii-edwardsii } \\
\text { K. edwardsii-atlantae } \\
\text { K. pneumoniae } \\
K . \text { rhinoscleroma }\end{array}$ & $\begin{array}{r}31 \\
8 \\
6 \\
4 \\
1\end{array}$ & $\begin{array}{l}2 \\
5 \\
0 \\
1 \\
0\end{array}$ & $\begin{array}{l}3 \\
6 \\
0 \\
0 \\
0\end{array}$ & $\begin{array}{r}13 \\
2 \\
2 \\
0 \\
0\end{array}$ & $\begin{array}{r}15 \\
0 \\
4 \\
4 \\
1\end{array}$ \\
\hline
\end{tabular}

TABLE IV

RESULTS OF ANTIBIOTIC SENSITIVITY TESTS OF 50 STRAINS

Percentage of Strains Resistant to

Penicillin Streptomycin Tetracycline $\begin{aligned} & \text { Chlor- } \\ & \text { amphenicol }\end{aligned}$ Erythromycin Novobiocin Sulphonamid

\begin{tabular}{|c|c|c|c|c|c|c|c|}
\hline $\begin{array}{l}\text { K. aerogenes } \\
K . \text { edwardsii-edwardsii } \\
K . \text { edwardsii-atlantae } \\
\text { K. pneumoniae }\end{array}$ & $\begin{array}{r}100 \\
86 \\
100 \\
100\end{array}$ & $\begin{array}{r}28 \\
57 \\
20 \\
0\end{array}$ & $\begin{array}{r}20 \\
43 \\
0 \\
0\end{array}$ & $\begin{array}{r}12 \\
29 \\
0 \\
0\end{array}$ & $\begin{array}{l}56 \\
43 \\
40 \\
50\end{array}$ & $\begin{array}{l}44 \\
43 \\
20 \\
50\end{array}$ & $\begin{array}{l}56 \\
43 \\
80 \\
50\end{array}$ \\
\hline
\end{tabular}


Cowan et al. based their characters on the study of seven strains only.

The use of a mouse virulence test, which has been suggested as a means of distinguishing $K$. aerogenes from the true Friedlander's bacillus (Stokes, 1955), has not been found to be completely reliable. The majority of the species $K$. edwardsii var edwardsii are mouse-virulent and the majority of $K$. aerogenes are avirulent but exceptions occur.

There appears to be no clear-cut differentiation into pathogenic and saprophytic species of Klebsiella with respect to man although the evidence does suggest that there is a wide variation in virulence between the different species. It is worth noting that both $K$. aerogenes and $K$. edwardsii var edwardsii have been isolated from the lung at necropsy from patients dying of pneumonia and both have been associated with the formation of a lung abscess. Nonetheless there appears to be a distinct difference in the pathogenicity of the two species, for in cases in which $K$. aerogenes was isolated only three out of 31 strains were associated with severe disease (one fatal case), whereas in cases in which the organism isolated was $K$. edwardsii var edwardsii six out of eight strains were associated with severe disease (five fatal cases). Also while 15 out of $31 \mathrm{~K}$. aerogenes strains were associated with trivial infections none of the $K$. edwardsii var edwardsii strains was isolated from such a case.

Cowan et al. consider that the strains they designate $K$. edwardsii var edwardsii and $K$. edwardsii var atlantae are closely related. However, the present study indicated a distinct difference with regard to their pathogenicity for man which might justify their being regarded as different species.

A point of nomenclature arises. It seems that the $K$. pneumoniae of Cowan et al. is unworthy of the name and does not in fact represent the organism which has generally been known hitherto as Friedlander's bacillus or K. pneumoniae. This designation, it is suggested, would be more apt for $K$. edwardsii var edwardsii. This view is supported by the type of disease associated with these strains, which included five fatal cases of pneumonia, two cases of pneumonia going on to lung abscess, and one case of pneumonia, in contrast with the trivial chest infections associated with the three strains of $K$. pneumoniae. Moreover four of the strains of $K$. edwardsii var edwardsii which were tested were found to be capsular type 1 . This view is further supported by the work of Small and Julianelle (1923) who tested the biochemical properties of a number of Klebsiella strains of known origin. These contained six strains isolated from fatal cases of pneumonia but only one fermented dulcite which is a key sugar for the $K$. pneumoniae of Cowan et al.
Similarly Edwards (1929) examined amongst a collection of strains of diverse origin 14 strains of Klebsiella said to have come from cases of human pneumonia. Their exact origin is not indicated but presumably the majority were isolated from sputum. If results of the methyl red, Voges-Proskauer, and dulcite fermentation tests are examined it will be found that 10 strains are clearly $K$. aerogenes. Of the four strains which were methyl red positive, VogesProskauer negative, and therefore could be either $K$ pneumoniae or $K$. edwardsii var edwardsii, only one fermented dulcite.

Table III records the percentage of strains for each species of Klebsiella resistant to the various antibiotics tested. The total number of strains tested for each species is small, particularly for species other than $K$. aerogenes, but the result suggests that there is probably no very striking difference in the antibiotic sensitivity pattern of the different species.

To summarize, for the clinical bacteriologist it would seem worthwhile as a result of the present study to divide the genus Klebsiella into species or types on the basis of the simple biochemical tests proposed by Cowan et al. (1960). The highly pathogenic $K$. edwardsii can be readily distinguished from the much less pathogenic $K$. aerogenes and the other species of Klebsiella. In clinical practice the classification of Cowan et al. might, with advantage, be simplified and modified. Klebsiella could be reported as $K$. aerogenes, $K$. pneumoniae (substituting this specific name for edwardsii var edwardsii) and $\mathrm{K}$. species. Such a classification would be useful to clinicians because it would use familiar terms and convey something of the clinico-pathological significance of the organisms.

We are indebted to Dr. Ida Ørskov of the State Serum Institute, Copenhagen, for typing some of our Klebsiella strains and for her advice throughout the investigation. We should also like to thank Dr. J. L. Pinniger and Mr. W. B. Yeoman for their comments on the paper.

\section{REFERENCES}

Bloomfield, A. L. (1958). A Bibliography of Internal Medicine; Communicable Diseases, p. 89. University of Chicago press.

Cowan, S. T., Steel, K. J., Shaw, C., and Duguid, J. P. (1960). J. gen. Microbiol., 23, 601.

Edwards, P. R. (1929), J. Bact., 17, 339.

Kauffmann, F. (1951). Enterobacteriaceae, p. 217. Munksgaard, Copenhagen.

Møller, V. (1954). Acta path. microbiol. scand., 36, 158.

Ørskov, I. (1955). Ibid., 36, 454.

Rawlins, G. A. (1955). J. med. Lab. Technol., 13, 133.

Shaw, C., and Clarke, P. H. (1955). J. gen. Microbiol., 13, 155.

Small, J. C., and Julianelle, L. A. (1923). J. infect. Dis., 32, 456.

Stokes, E. J. (1955). Clinical Bacteriology, p. 109. Arnold, London.

Weiss, W., Eisenberg, G. M., Alexander, J. D., and Flippin, H. F. (1954). Amer. J. med. Sci., 228, 148.

Wilson, G. S., and Miles, A. A. (1948). Principles of Bacteriology and Immunity, 3rd ed., p. 675. Arnold, London. 